\title{
Physician follow-up and long-term use of evidence-based medication for patients with hypertension who were discharged from an emergency department: a prospective cohort study
}

\author{
Clare L. Atzema MD MSc, Bing Yu PhD, Michael J. Schull MD MSc, Cynthia A. Jackevicius PharmD MSc, \\ Noah M. Ivers MD PhD, Douglas S. Lee MD PhD, Paula Rochon MD MSc, Peter C. Austin PhD
}

Abstract

Background: More than $25 \%$ of the population has hypertension. The number of patients seeking care for hypertension in emergency departments has increased by more than $60 \%$ in the last decade, with less than $10 \%$ of these patients subsequently admitted to hospital. Managing physicians recommend early follow-up to patients who are discharged from the emergency department, but there is a paucity of literature assessing the impact or timing of follow-up on patient outcomes.

Methods: Using a population-based cohort design, we included patients more than 65 years of age who were discharged from an Ontario emergency department with a primary diagnosis of hypertension between 2007 and 2014. We identified 2 cohorts: an incident cohort, and a cohort in which patients were on no more than 1 class of evidence-based antihypertensive medication at the time of presentation. Using logistic regression, we assessed the association of early follow-up care (within 7 d) and basic care (8-30 d), compared with no care within 30 days, on patient use of a new evidence-based antihypertensive medication 1 year later.

Results: Our study included 2088 patients with a new diagnosis of hypertension (the first cohort), and 6420 patients in the second cohort. Of patients with new diagnoses, $48.2 \%$ and $30.2 \%$ obtained early and basic follow-up care, respectively, compared with $50.0 \%$ and $30.9 \%$ of patients in the second cohort. Compared with patients without follow-up care within 30 days, the adjusted odds of filling an evidence-based antihypertensive medication prescription 1 year later in the incident group were 2.36 (95\% confidence interval [Cl] 1.86-2.99) for those who received early care, and $2.00(95 \% \mathrm{Cl} 1.55-2.58)$ for those who received basic care. The adjusted odds in the second cohort were $2.12(95 \% \mathrm{Cl} 1.84-2.43)$ and $1.96(95 \% \mathrm{Cl} 1.69-2.27)$, respectively.

Interpretation: Early follow-up care after leaving an emergency department with a diagnosis of hypertension was associated with improved long-term use of evidence-based antihypertensive medication. As patients increasingly present to the emergency department for hypertension, a formal, timely follow-up care system could improve patient use of evidence-based antihypertensive medication.

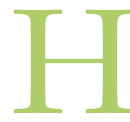

ypertension affects about $25 \%$ of Canadians, $30 \%$ of Americans, and 1 billion people worldwide. ${ }^{1-3}$ Increasing disease prevalence secondary to the aging of the population and other factors has resulted in an increasing number of visits to emergency departments for the disease ${ }^{2,4}$ : hypertension visits increased by $36 \%$ between 2006 and 2012 in the United States, ${ }^{5}$ and by $65 \%$ between 2002 and 2012 in Canada. ${ }^{6}$ Most of these patients are discharged home after their emergency episode, and that proportion has increased over time.,

Managing physicians typically advise these patients to follow-up with their primary care provider or cardiologist within 1 week, ${ }^{7}$ although there is a paucity of evidence to substantiate that time frame. Canadian guidelines recommend follow-up within 1 month, although emergency department visits are not specifically addressed. ${ }^{8}$ To the best of our knowl- edge, no data support an optimal follow-up period for patients who are discharged from an emergency department.

We hypothesized that patients who are seen later, when the anxiety around the emergency visit has abated and no adverse event has occurred, may be less motivated to continue taking medication for hypertension in the long term compared with patients who are seen soon after their emergency visit. In this study, we aimed to determine whether

\section{Competing interests: None declared.}

This article has been peer reviewed.

Correspondence to: Clare Atzema, clare.atzema@ices.on.ca CMAJ Open 2018. DOI:10.9778/cmajo.20170119 
obtaining follow-up care after discharge from the emergency setting and whether the timing of that care was associated with use of evidence-based medication 1 year later.

\section{Methods}

\section{Study design and data sources}

Patients were identified from the Canadian Institute for Health Information (CIHI) National Ambulatory Care Reporting System, which includes abstracted data on all visits made to emergency departments in Ontario. ${ }^{9}$ The institute's Discharge Abstract Database contains abstracted information on all hospital admissions in Ontario. ${ }^{10}$ Both databases use the International Statistical Classification of Diseases and Related Health Problems, 10th Revision (ICD-10), to code diagnoses. ${ }^{11}$ The Registered Persons Database contains mortality information about Ontario residents, including deaths outside of hospitals. ${ }^{12}$ The Ontario Health Insurance Plan (OHIP) holds billings made by physicians for services and procedures provided in the office, home or long-term care facility, or by telephone. ${ }^{10}$ Because Ontario has universal health care coverage, these billings include most of the medically necessary care provided in the province.

The Physician Database contains physician specialty information, and is a compilation of data gathered from billings to OHIP, the Corporate Provider Database ${ }^{13}$ and the Ontario Physician Human Resources Data Centre. ${ }^{14}$ The latter conducts an annual survey of one-third of physician offices in the province to update their database. The Ontario Drug Database contains the dates on which prescriptions are filled and the quantity and dose of the medication dispensed for residents of Ontario aged 65 years and older. ${ }^{10}$ Data were linked between data sets using unique encoded identifiers and analyzed at our research institute.

\section{Study population}

Patients who were seen and discharged from an emergency department with a primary diagnosis (first listed on the chart) of hypertension between Apr. 1, 2007, and Mar. 31, 2014, were eligible for inclusion. We restricted the cohort to primary diagnoses because we have validated the primary diagnosis ICD-10 code for hypertension in the National Ambulatory Care Reporting System database. Specifically, we pulled emergency department charts from 5 tertiary and community emergency departments in Ontario to confirm that the primary diagnosis was hypertension (positive predictive value $95.7 \%$ [95\% confidence interval (CI) $94.6 \%-96.7 \%]$ ). ${ }^{6}$ The median presenting blood pressure in the 1580 charts analyzed was 181/97 mm Hg (interquartile range [IQR] 164-200/85-109). ${ }^{6}$

We created an incident cohort that included patients with a new diagnosis of hypertension by excluding patients who had a diagnosis (or a comorbidity listing) of hypertension (ICD-10 codes I10-I13) in the previous 5 years in any of the referenced databases. Because this constitutes only some of the patients seen in the emergency department with a primary diagnosis of hypertension (most are already taking an antihypertensive agent), we created a second cohort in which we did not apply this exclusion criteria; however, we excluded patients who were taking more than 1 class of evidence-based medication for hypertension (including $\beta$-blockers, longacting dihydropyridine calcium-channel blockers, angiotensin converting enzyme inhibitors or angiotensin receptor blockers, or thiazide diuretic agents). ${ }^{8,15,16} \mathrm{We}$ excluded patients taking more than 1 antihypertensive agent because we were interested in the effect of follow-up care on the use of new evidence-based antihypertensive medications; the more antihypertensive medications a patient is already taking, the less likely the physician might be to prescribe another antihypertensive medication (owing to concern over drug interactions, and lack of physician comfort with multiple antihypertensive medication classes). Thus, in the second cohort, we included both incident cases of hypertension and patients with a previous diagnosis of hypertension who took either no evidencebased antihypertensive medication or a single class only.

We excluded patients younger than 66 years of age because of a lack of comprehensive prescription medication data for this age group. In addition, we excluded repeat visits by the same patient, patients who died in the emergency department, and patients who were admitted to hospital at the end of their emergency visit. Furthermore, we excluded visits to specialty emergency departments (such as pediatric sites) and patients who did not have a family physician, because this might markedly affect access to follow-up care and use of evidence-based medication. However, our sensitivity analyses did include these patients. Finally, we excluded patients who died within 410 days of the emergency visit, because they would not be available to have prescriptions filled during the entire period of follow-up.

\section{Outcome measure}

The primary outcome measure was a new prescription filled for an evidence-based medication for hypertension at 1 year of discharge from an emergency department (i.e., within 320 and 410 days). Changes from one class of medication to another (i.e., a new prescription with discontinuation of a previous evidence-based antihypertensive medication, resulting in the same overall number of evidence-based antihypertensive medications) were not counted. Prescription fills were chosen instead of mortality because the 1-year all-cause mortality for patients discharged from the emergency department with a primary diagnosis of hypertension is very low $(2.5 \%),{ }^{6}$ and mortality secondary to hypertension (with the uncommon exception of hypertensive emergencies) are due to diseases that take years to develop secondary to hypertension (e.g., coronary artery disease leading to acute myocardial infarction, stroke, heart failure). We chose this outcome given the proven causal relationship between evidence-based medication and long-term morbidity and mortality in patients with hypertension. $8,15,16$

\section{Data analysis}

The independent variable of interest was type of follow-up. We defined follow-up within 7 days as "early care" and between days 8 and 30 as "basic care." Follow-up visits included those made to a physician who was likely to provide 
ongoing prescriptions for hypertension management: family physicians, cardiologists or internists. We assessed baseline characteristics overall and by follow-up type using $\chi^{2}$, oneway analysis of variance and Kruskal-Wallis, as appropriate. We used logistic regression to adjust for differences between patients in different follow-up care groups, accounting for clustering within hospitals using generalized estimating equations. ${ }^{17} \mathrm{We}$ chose logistic regression because we wished to determine the odds of a prescription fill 1 year later, as opposed to how quickly a medication was filled after discharge (i.e., the instantaneous hazard). In addition, we anticipated mortality would be low, and would therefore be unlikely to substantially alter the results of logistic regression.

We chose model covariates based on our work in the area and a review of the literature. ${ }^{6-8,15,16,18}$ These covariates included patient demographics, comorbidities, hospital and emergency department details, and family physician characteristics. We included the adjusted diagnosis group (ADG) score, which is used in an ambulatory patient population to adjust for illness severity ${ }^{19}$ (similar in principle to how the Charleson Comorbidity Score is used among patients who have been previously admitted to hospital ${ }^{20}$ ). The ADG score tabulates the number of outpatient care visits a patient has for a variety of diseases, providing a measure of resource use for each patient. We performed a sensitivity analysis in which we included the patients who did not have a family doctor in the logistic regression models. All analyses were performed with SAS software (version 9.3, SAS Institute Inc., Cary, NC).

\section{Ethics approval}

This study was approved by the Sunnybrook Health Sciences Centre Research Ethics Board.

\section{Results}

We excluded $14.3 \%$ of patients from the incident cohort and $7.9 \%$ of patients the second cohort because of a lack of family physician. In the incident cohort, 2088 patients were seen at 150 emergency departments (Figure 1). Of these, 1.2\% died within 410 days of the emergency visit, 1007 (48.2\%) obtained early follow-up, and 631 (30.2\%) had delayed follow-up, leaving 450 (21.6\%) without 30-day follow-up (Table 1). Among patients without 30-day follow-up, 67 (3.2\%) had no relevant follow-up visits up to 1 year later. The median age of patients in the early and no follow-up groups was 72 years, and was 73 years in the group who received basic care. There were more men in the group without 30-day follow-up (41.6\%) compared with the early (33.4\%) and basic (36.5\%) groups.

In the second cohort, 6420 patients were seen at 156 emergency departments (Figure 2). Of these patients, 3.6\% died within 410 days of the emergency visit, 3212 (50.1\%) received early follow-up, 1986 (30.9\%) received basic follow-up, and $1222(19.0 \%)$ received no follow-up care within 30 days (Table 2). The latter group included 159 (2.5\%) patients who had no relevant follow-up visits up to 1 year later. The median age of patients was 74 years in each group, with no substantial difference between numbers of men and women.

\section{Follow-up timing and prescriptions filled in the incident cohort}

In the incident cohort, 1200 (57.5\%) patients filled a new prescription for an evidence-based antihypertensive medication at 1 year post-discharge. The proportion of patients filling prescriptions 1 year later decreased as time to follow-up care increased (Table 1). In the adjusted analysis, early follow-up was associ-

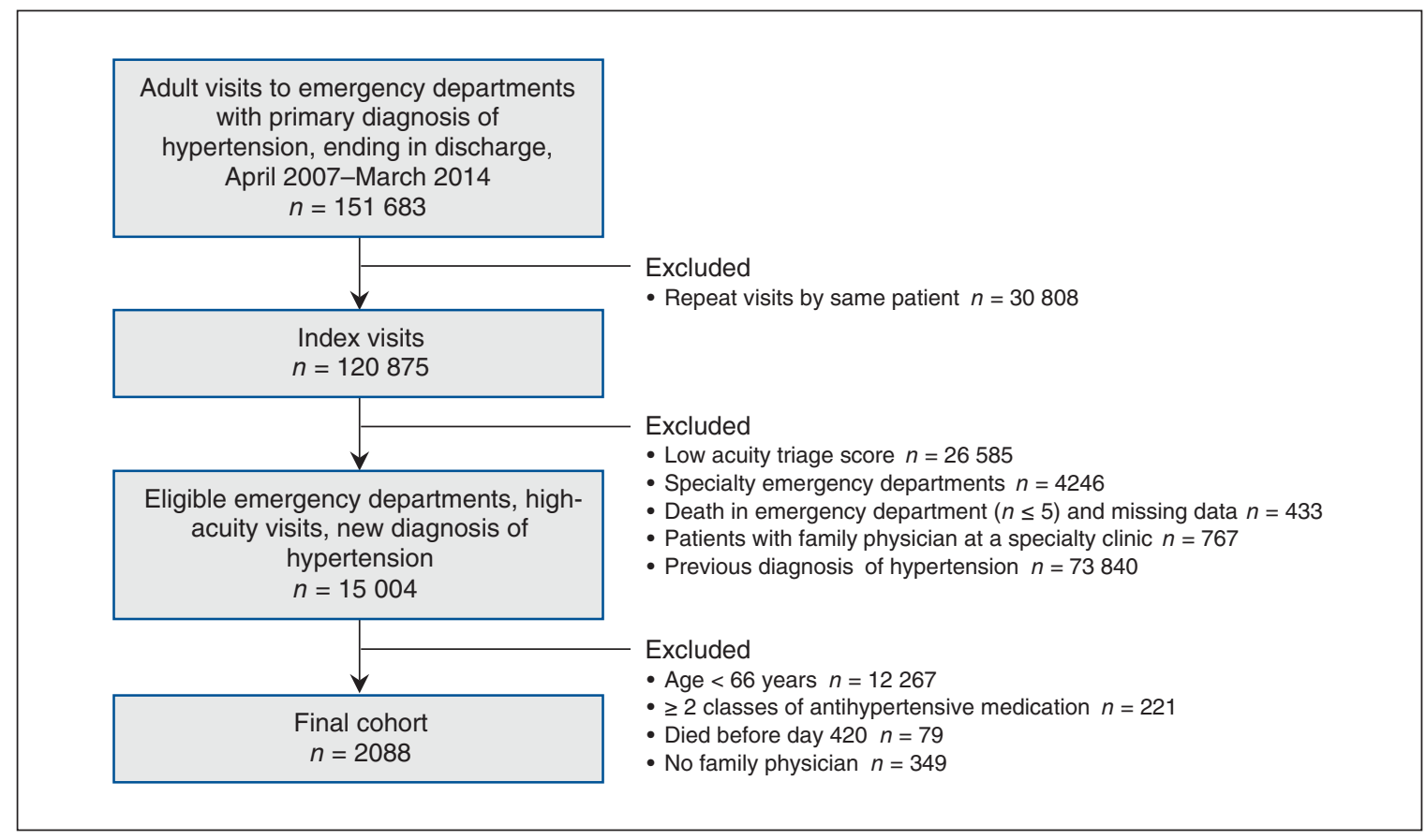

Figure 1: Flow of patients in the incident cohort through the study. 


\begin{tabular}{|c|c|c|c|c|c|}
\hline Characteristic & $\begin{array}{c}\text { Total, no. }(\%)^{*} \\
n=2088\end{array}$ & \multicolumn{3}{|c|}{ Follow-up care, no. $(\%)^{\star}$} & $p$ value \\
\hline Age, yr, mean $(95 \% \mathrm{Cl})$ & $74.1(73.9-74.4)$ & $73.8(73.4-74.2)$ & $74.7(74.1-75.2)$ & $74.2(73.6-74.9)$ & 0.04 \\
\hline \multicolumn{6}{|l|}{ Income quintile } \\
\hline 1 (lowest) & $401(19.2)$ & $181(18.0)$ & $119(18.9)$ & $101(22.4)$ & \multirow[t]{4}{*}{0.38} \\
\hline 2 & $443(21.2)$ & $203(20.2)$ & $148(23.5)$ & $92(20.4)$ & \\
\hline 3 & $384(18.4)$ & $195(19.4)$ & $112(17.7)$ & $77(17.1)$ & \\
\hline 4 & $428(20.5)$ & $207(20.6)$ & $125(19.8)$ & $96(21.3)$ & \\
\hline Heart failure & $56(2.7)$ & $25(2.5)$ & $23(3.6)$ & $8(1.8)$ & 0.15 \\
\hline Atrial fibrillation & $160(7.7)$ & $79(7.8)$ & $52(8.2)$ & $29(6.4)$ & 0.53 \\
\hline Acute myocardial infarction & $132(6.3)$ & $66(6.6)$ & $41(6.5)$ & $25(5.6)$ & 0.75 \\
\hline Coronary artery disease & $90(4.3)$ & $39(3.9)$ & $31(4.9)$ & $20(4.4)$ & 0.59 \\
\hline CABG & $15(0.7)$ & $t$ & $8(1.3)$ & $t$ & 0.11 \\
\hline ICD/PPM & $10(0.5)$ & $\dagger$ & $\dagger$ & $\dagger$ & 0.99 \\
\hline Stroke & $57(2.7)$ & $12(1.2)$ & $26(4.1)$ & $19(4.2)$ & $<0.001$ \\
\hline Diabetes mellitus & $292(14.0)$ & $140(13.9)$ & $90(14.3)$ & $62(13.8)$ & 0.97 \\
\hline Dementia & $91(4.4)$ & $41(4.1)$ & $29(4.6)$ & $21(4.7)$ & 0.82 \\
\hline COPD & $345(16.5)$ & $153(15.2)$ & $116(18.4)$ & $76(16.9)$ & 0.23 \\
\hline \multicolumn{6}{|l|}{ ED visit details } \\
\hline ED triage score, $\S 1$ or 2 & $706(33.8)$ & $348(34.6)$ & $223(35.3)$ & $135(30.0)$ & 0.15 \\
\hline Ambulance arrival & $289(13.8)$ & $122(12.1)$ & $111(17.6)$ & $56(12.4)$ & 0.005 \\
\hline \multicolumn{6}{|l|}{ Time of presentation } \\
\hline 00:00-07:59 & $174(8.3)$ & $80(7.9)$ & $50(7.9)$ & $44(9.8)$ & \multirow[t]{3}{*}{0.13} \\
\hline 08:00-15:59 & $936(44.8)$ & $429(42.6)$ & $304(48.2)$ & $203(45.1)$ & \\
\hline 16:00-23:59 & $978(46.8)$ & $498(49.5)$ & 277 (43.9) & $203(45.1)$ & \\
\hline Day of presentation, weekend & $577(27.6)$ & $305(30.3)$ & $156(24.7)$ & $116(25.8)$ & 0.03 \\
\hline ED physician age, median (IQR) & $43.0(36.0-50.0)$ & $42.0(37.0-49.0)$ & $43.0(37.0-50.0)$ & $43.0(37.0-51.0)$ & 0.03 \\
\hline ED physician sex, female & $467(22.4)$ & $245(24.3)$ & $126(20.0)$ & $96(21.3)$ & 0.10 \\
\hline \multicolumn{6}{|l|}{ ED physician years of practice, yr } \\
\hline $0-5$ & $507(24.3)$ & $265(26.3)$ & $137(21.7)$ & $105(23.3)$ & \multirow[t]{4}{*}{0.11} \\
\hline $6-10$ & $389(18.6)$ & $184(18.3)$ & $126(20.0)$ & $79(17.6)$ & \\
\hline $11-15$ & $379(18.2)$ & $187(18.6)$ & $122(19.3)$ & $70(15.6)$ & \\
\hline$>15$ & $813(38.9)$ & $371(36.8)$ & $246(39.0)$ & $196(43.6)$ & \\
\hline \multicolumn{6}{|l|}{ ED physician main specialty } \\
\hline 3-year EM & $1024(49.0)$ & $508(50.4)$ & $304(48.2)$ & $212(47.1)$ & \multirow[t]{4}{*}{$<0.001$} \\
\hline 5-year EM & $212(10.2)$ & $125(12.4)$ & $44(7.0)$ & $43(9.6)$ & \\
\hline FM & $794(38.0)$ & 341 (33.9) & $267(42.3)$ & $186(41.3)$ & \\
\hline Other & $58(2.8)$ & $33(3.3)$ & $16(2.5)$ & $9(2.0)$ & \\
\hline
\end{tabular}




\begin{tabular}{|c|c|c|c|c|c|}
\hline \multirow[b]{2}{*}{ Characteristic } & \multirow[b]{2}{*}{$\begin{array}{c}\text { Total, no. }(\%)^{*} \\
n=2088\end{array}$} & \multicolumn{3}{|c|}{ Follow-up care, no. $(\%)^{*}$} & \multirow[b]{2}{*}{$p$ value } \\
\hline & & $\begin{array}{c}1-7 d \\
n=1007\end{array}$ & $\begin{array}{l}8-30 \mathrm{~d} \\
n=631\end{array}$ & $\begin{array}{c}\text { No. 30-d follow-up } \\
n=450\end{array}$ & \\
\hline \multicolumn{6}{|l|}{ ED visit details cont'd } \\
\hline \multicolumn{6}{|l|}{ Hospital type } \\
\hline Community & $1585(75.9)$ & $786(78.1)$ & $483(76.5)$ & $316(70.2)$ & \multirow[t]{3}{*}{$<0.001$} \\
\hline Small & $180(8.6)$ & $60(6.0)$ & $62(9.8)$ & $58(12.9)$ & \\
\hline Teaching & $323(15.5)$ & $161(16.0)$ & $86(13.6)$ & $76(16.9)$ & \\
\hline \multicolumn{6}{|l|}{ Family physician details } \\
\hline Family physician age, median (IQR) & $55.0(47.0-62.0)$ & $56.0(47.0-63.0)$ & $55.0(47.0-63.0)$ & $55.0(45.0-62.0)$ & 0.09 \\
\hline Family physician sex, female & $502(24.0)$ & $250(24.8)$ & $144(22.8)$ & $108(24.0)$ & 0.65 \\
\hline \multicolumn{6}{|l|}{ Family physician years of practice, $y r$} \\
\hline $0-5$ & $95(4.5)$ & $37(3.7)$ & $32(5.1)$ & $26(5.8)$ & \multirow[t]{4}{*}{0.27} \\
\hline $6-10$ & $139(6.7)$ & $62(6.2)$ & $39(6.2)$ & $38(8.4)$ & \\
\hline $11-15$ & $183(8.8)$ & $94(9.3)$ & $54(8.6)$ & $35(7.8)$ & \\
\hline$>15$ & $1671(80.0)$ & $814(80.8)$ & $506(80.2)$ & $351(78.0)$ & \\
\hline \multicolumn{6}{|l|}{ Family physician remuneration model } \\
\hline $\mathrm{CCM} / \mathrm{FHG}$ & $727(34.8)$ & $388(38.5)$ & $212(33.6)$ & $127(28.2)$ & \multirow[t]{5}{*}{$<0.001$} \\
\hline FHN & $134(6.4)$ & $41(4.1)$ & $63(10.0)$ & $30(6.7)$ & \\
\hline $\mathrm{FHO} / \mathrm{FHT}$ & $536(25.7)$ & $239(23.7)$ & $153(24.2)$ & $144(32.0)$ & \\
\hline $\mathrm{FHO/noFHT}$ & $486(23.3)$ & $233(23.1)$ & $157(24.9)$ & $96(21.3)$ & \\
\hline NA/FFS & $205(9.8)$ & $106(10.5)$ & $46(7.3)$ & $53(11.8)$ & \\
\hline \multicolumn{6}{|l|}{ Outcome } \\
\hline New EBM prescription fill 1 year later & $1200(57.5)$ & $626(62.2)$ & $376(59.6)$ & $198(44.0)$ & $<0.001$ \\
\hline \multicolumn{6}{|c|}{ 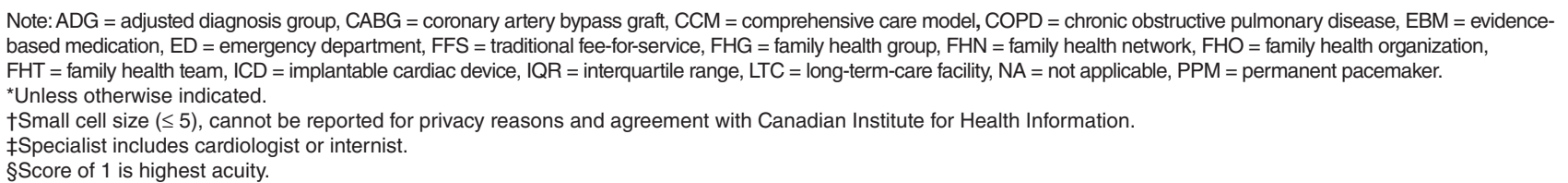 } \\
\hline
\end{tabular}

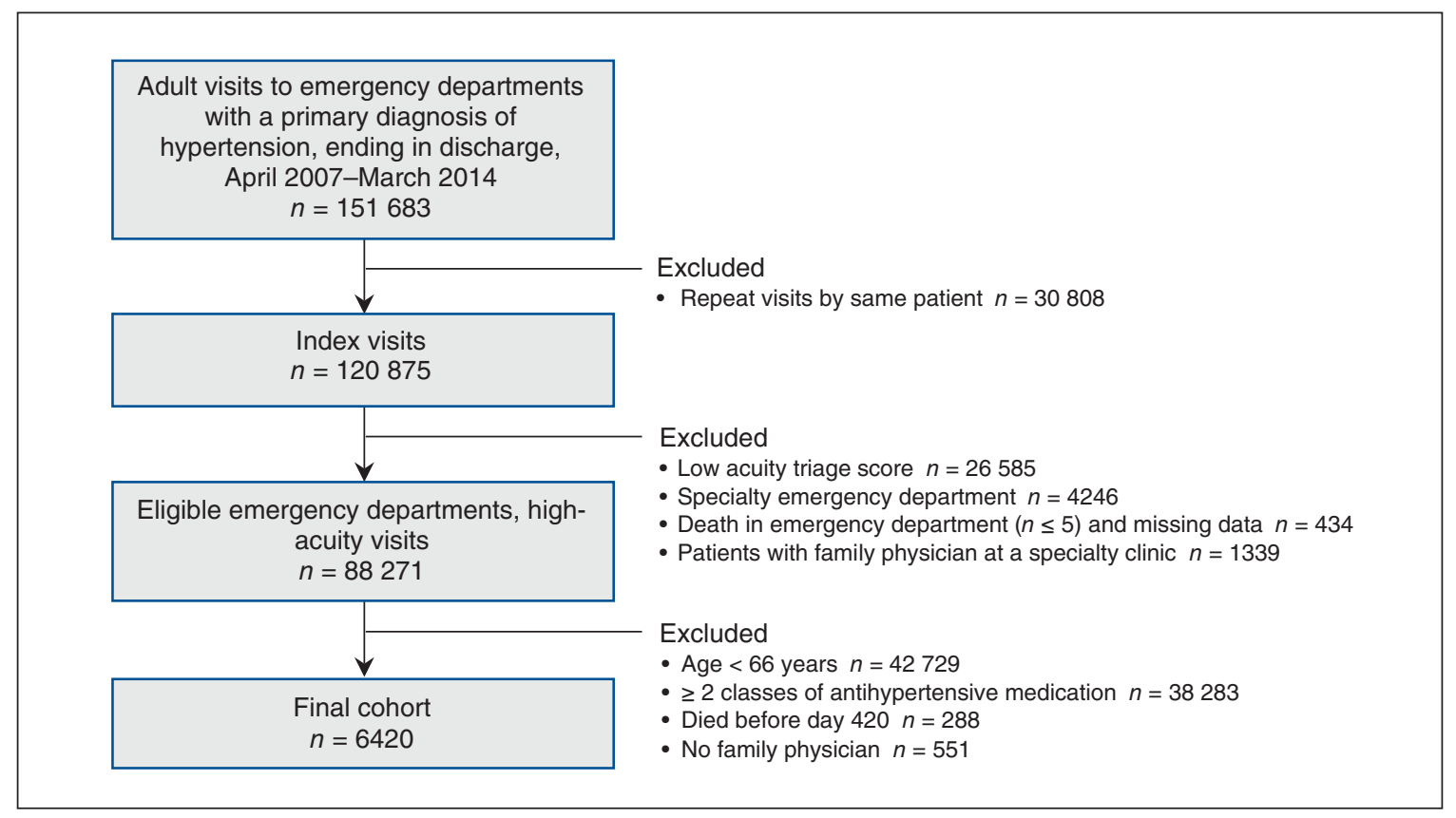

Figure 2: Flow of patients in the second cohort through the study. 
Table 2 (part 1 of 2): Follow-up in hypertension patients on no more than 1 antihypertensive medication

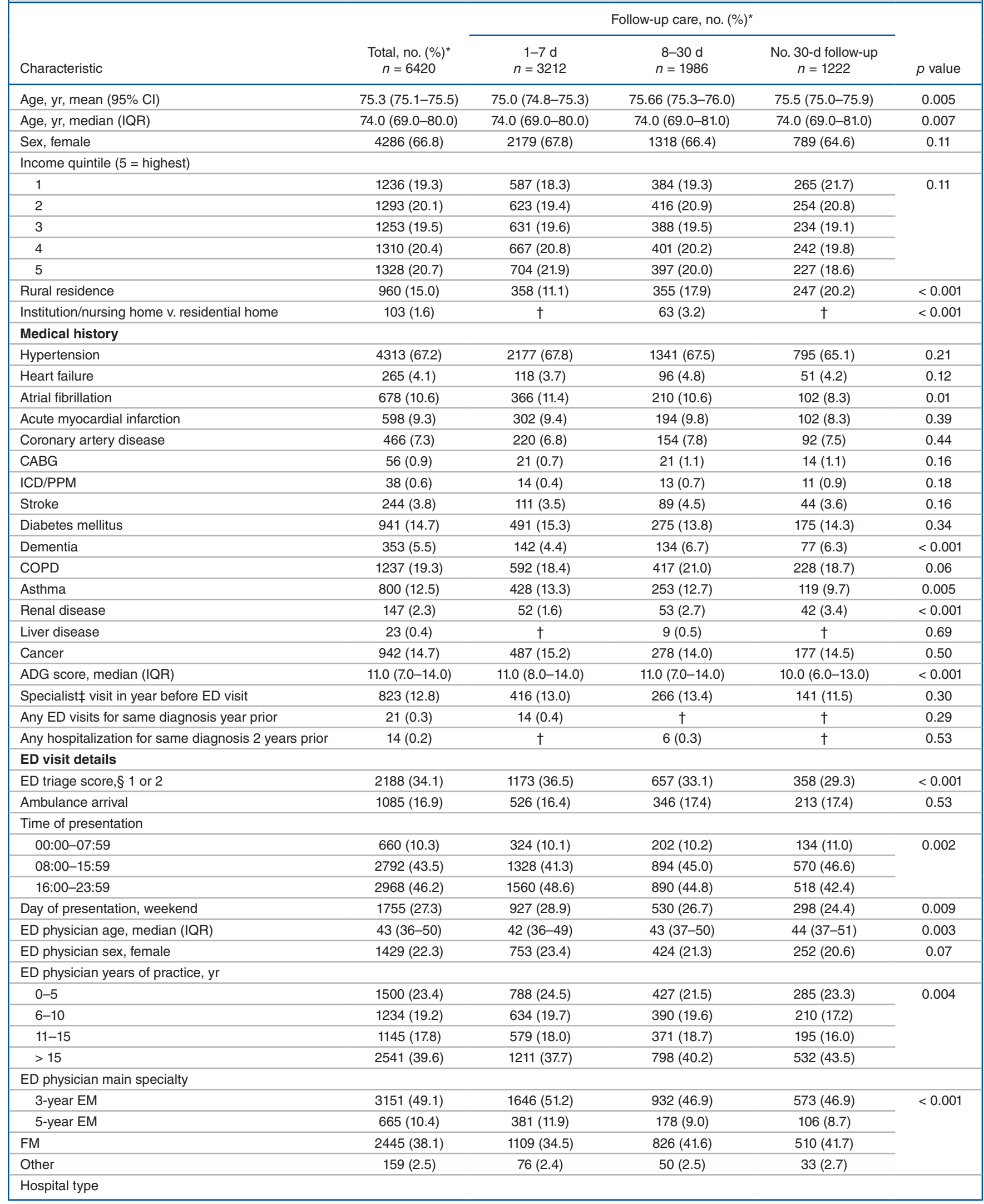




\begin{tabular}{|c|c|c|c|c|c|}
\hline \multirow[b]{2}{*}{ Characteristic } & \multirow[b]{2}{*}{$\begin{array}{c}\text { Total, no. }(\%)^{*} \\
n=6420\end{array}$} & \multicolumn{3}{|c|}{ Follow-up care, no. $(\%)^{*}$} & \multirow[b]{2}{*}{$p$ value } \\
\hline & & $\begin{array}{c}1-7 d \\
n=3212\end{array}$ & $\begin{array}{c}8-30 d \\
n=1986\end{array}$ & $\begin{array}{l}\text { No. 30-d follow-up } \\
\quad n=1222\end{array}$ & \\
\hline \multicolumn{6}{|l|}{ ED visit details cont'd } \\
\hline Community & 4964 (77.3) & 2527 (78.7) & $1532(77.1)$ & 905 (74.1) & \multirow[t]{3}{*}{$<0.00$} \\
\hline Small & $460(7.2)$ & $162(5.0)$ & 168 (8.5) & $130(10.6)$ & \\
\hline Teaching & $996(15.5)$ & $523(16.3)$ & $286(14.4)$ & $187(15.3)$ & \\
\hline \multicolumn{6}{|l|}{ Family physician details } \\
\hline Family physician age, median (IQR) & $55.0(47.0-62.0)$ & $55.0(47.0-62.0)$ & $54.0(46.0-62.0)$ & $55.0(47.0-62.0)$ & 0.27 \\
\hline Family physician sex, female & $1661(25.9)$ & $867(27.0)$ & $494(24.9)$ & $300(24.5)$ & 0.12 \\
\hline \multicolumn{6}{|l|}{ Family physician years of practice, $y r$} \\
\hline $0-5$ & $285(4.4)$ & $121(3.8)$ & $98(4.9)$ & $66(5.4)$ & \multirow[t]{4}{*}{0.02} \\
\hline $6-10$ & 407 (6.3) & $182(5.7)$ & $143(7.2)$ & $82(6.7)$ & \\
\hline $11-15$ & $586(9.1)$ & $284(8.8)$ & $193(9.7)$ & $109(8.9)$ & \\
\hline$>15$ & $5142(80.1)$ & $2625(81.7)$ & $1552(78.1)$ & $965(79.0)$ & \\
\hline \multicolumn{6}{|l|}{ Family physician remuneration model } \\
\hline $\mathrm{CCM} / \mathrm{FHG}$ & $2516(39.2)$ & $1406(43.8)$ & $717(36.1)$ & $393(32.2)$ & \multirow[t]{5}{*}{$<0.001$} \\
\hline FHN & $408(6.4)$ & $137(4.3)$ & $166(8.4)$ & $105(8.6)$ & \\
\hline $\mathrm{FHO} / \mathrm{FHT}$ & $1433(22.3)$ & $638(19.9)$ & $463(23.3)$ & $332(27.2)$ & \\
\hline $\mathrm{FHO} / \mathrm{noFHT}$ & $1463(22.8)$ & $737(22.9)$ & $461(23.2)$ & $265(21.7)$ & \\
\hline NA/FFS & $600(9.3)$ & $294(9.2)$ & $179(9.0)$ & $127(10.4)$ & \\
\hline \multicolumn{6}{|l|}{ Outcome } \\
\hline New EBM prescription fill a year later & $3562(55.5)$ & $1894(59.0)$ & $1151(58.0)$ & 517 (42.3) & $<0.001$ \\
\hline \multicolumn{6}{|c|}{$\begin{array}{l}\text { Note: } A D G=\text { adjusted diagnosis group, } C A B G=\text { coronary artery bypass graft, } C C M=\text { comprehensive care model, } C O P D=\text { chronic obstructive pulmonary disease, } E B M=\text { evidence- } \\
\text { based medication, } E D=\text { emergency department, } F F S=\text { traditional fee-for-service, } F H G=\text { family health group, } F H N=\text { family health network, } F H O=\text { family health organization, } \\
F H T=\text { family health team, ICD }=\text { implantable cardiac device, IQR }=\text { interquartile range, } L T C=\text { long-term-care facility, } N A=\text { not applicable, PPM = permanent pacemaker. } \\
\text { *Unless otherwise indicated. } \\
\text { tSmall cell size }(\leq 5) \text {, cannot be reported for privacy reasons and agreement with Canadian Institute for Health Information. } \\
\text { fSpecialist includes cardiologist or internist. } \\
\text { §Score of } 1 \text { is highest acuity. }\end{array}$} \\
\hline
\end{tabular}

ated with more than double the odds of filling a prescription for an evidence-based antihypertensive medication 1 year later, relative to no follow-up care within 30 days (odds ratio [OR] 2.36, 95\% CI 1.86-2.99) (Figure 3 and Appendix 1, available at www. cmajopen.ca/content/6/2/E151/suppl/DC1). Follow-up care between days 8 and 30 after departure from the emergency department was independently associated with twice the odds of 1-year prescription fills (OR 2.00, 95\% CI 1.55-2.58). Five other variables were associated with a 1-year prescription fill: a high-acuity emergency triage score, and history of stroke or diabetes were associated with higher odds, whereas weekend presentation and a higher ADG score were associated with lower odds. All of the effect sizes were smaller relative to follow-up care. Results were similar in the sensitivity analysis.

\section{Follow-up timing and prescriptions filled in the second cohort}

In the second cohort, $3562(55.5 \%)$ patients filled a prescription for a new evidence-based antihypertensive medication 1 year after discharge from an emergency department. Again, the proportion of patients filling a prescription 1 year later decreased with increasing time to follow-up (Table 2). Early follow-up was associated with more than twice the adjusted odds of filling an evidence-based antihypertensive medication prescription, relative to no 30-day follow-up: OR 2.12 (95\% CI 1.84-2.43) (Figure 4 and Appendix 1). In addition, the odds were higher with follow-up care between days 8 and 30: OR 1.96 (95\% CI 1.69-2.27). In addition to ADG score and triage score, the other associated variables in this cohort included female sex, a history of hypertension, having seen a specialist in the previous year, and a family physician remuneration model that was primarily capitation-based. Results were similar in the sensitivity analysis.

\section{Interpretation}

In this population-based study involving people who were seen in the emergency setting with a new diagnosis of hypertension, we found that the odds of taking a proven medication to treat hypertension in the long term were $136 \%$ higher for patients who obtained physician follow-up within 1 week of presentation, compared with those who do not receive care within 30 days. The odds were still $100 \%$ higher for those who obtained care after the initial week but within 30 days. The association was similar but slightly weaker in the group that included patients who had a history of hypertension and possible antihypertensive use $(112 \%$ increase for those with early care, $96 \%$ increase with delayed care). These results provide the first evidence to support 


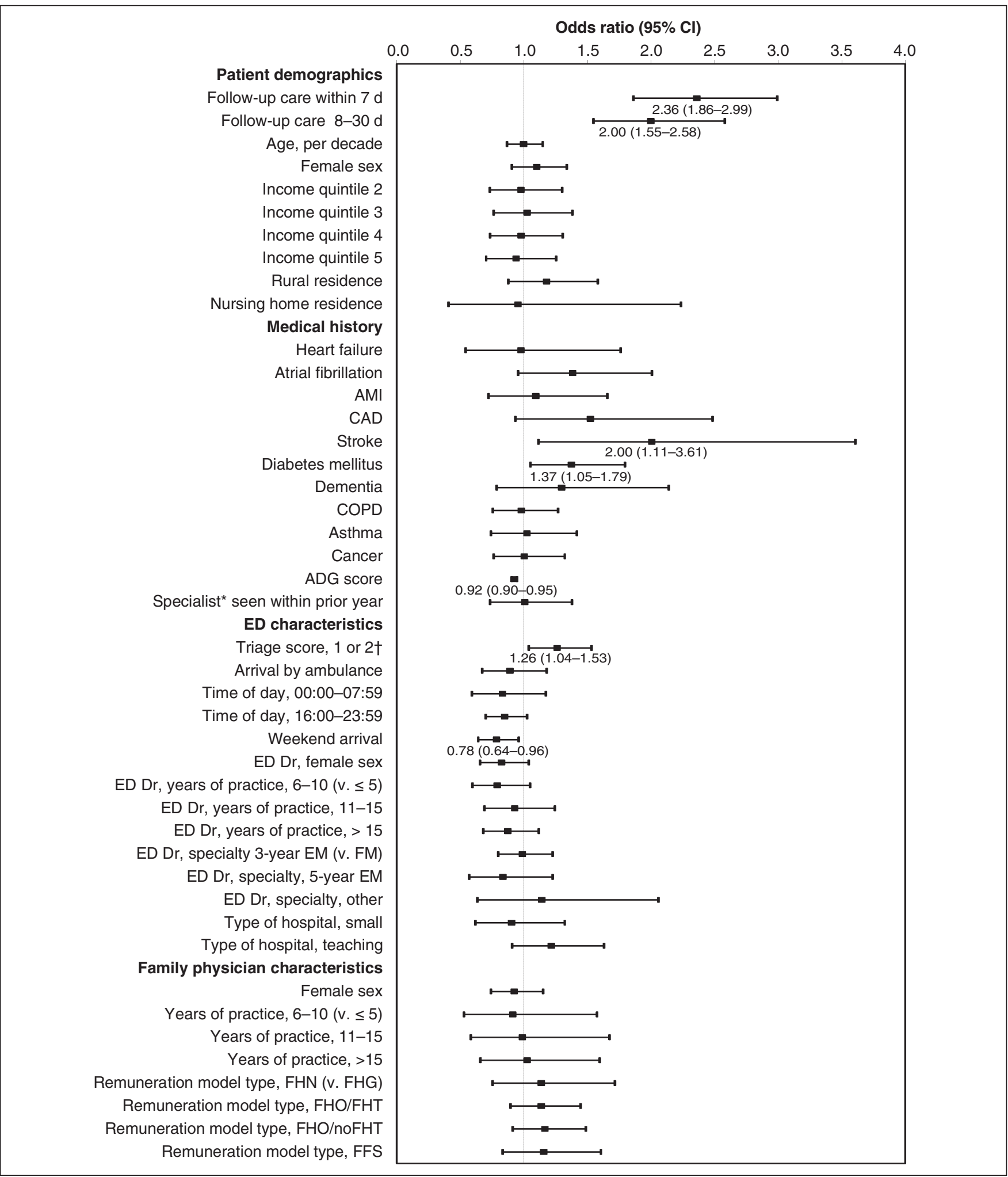

Figure 3: Adjusted odds of filling a prescription for a new evidence-based medication one year post-discharge from an emergency department among patients with a new diagnosis of hypertension. $A D G=$ adjusted diagnosis group, $A M I=$ acute myocardial infarction, $C A D=$ coronary artery disease, $\mathrm{Cl}=$ confidence interval, $\mathrm{COPD}=$ chronic obstructive pulmonary disease, $\mathrm{Dr}=$ doctor, $\mathrm{ED}=$ emergency department, $\mathrm{EM}=$ emergency medicine, FFS = traditional fee-for-service, FHG = family health group (primarily FFS), FHN = family health network (primarily capitation-based), $\mathrm{FHO}=$ family health organization (primarily capitation-based, offering slightly more services than FHN), FHT = family health team (not a remuneration model, entails funding for an interdisciplinary team, electronic health records, etc., for capitation-based models), FM $=$ family medicine. ${ }^{*}$ Specialist includes cardiologist or internist. $†$ Score of 1 is highest acuity. 
recommendations around follow-up care for these commonly seen patients, and can offer guidance to clinicians and administrators around when to advise or arrange follow-up care.
Previous work has found that, for patients discharged from the emergency setting with a new diagnosis of an ambulatory care-sensitive cardiovascular condition, the pre-

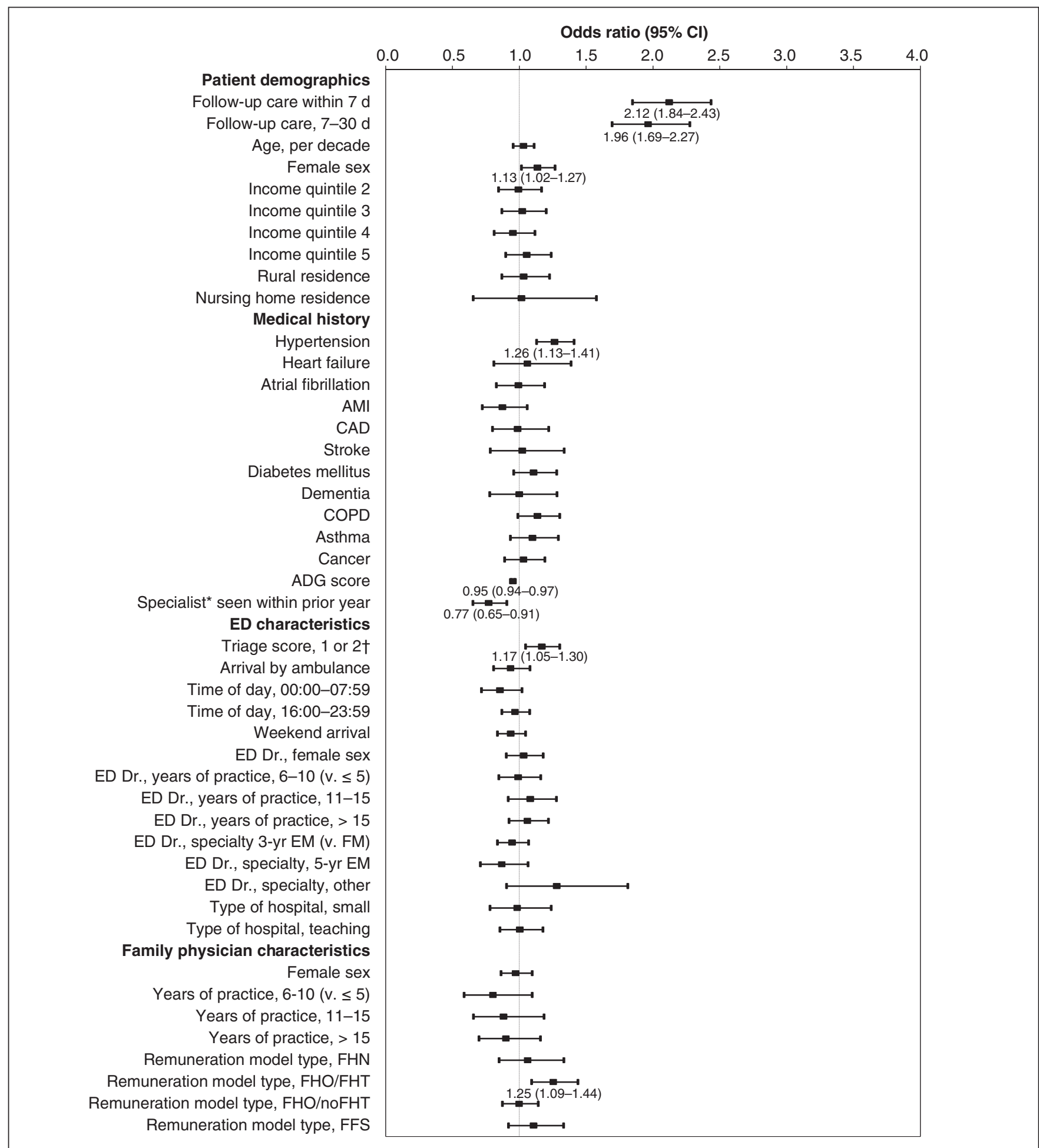

Figure 4: Adjusted odds of filling a prescription for a new evidence-based medication 1 year after discharge from an emergency department in the second cohort. $\mathrm{ADG}=$ adjusted diagnosis group, $\mathrm{AMI}=$ acute myocardial infarction, $\mathrm{CAD}=$ coronary artery disease, $\mathrm{Cl}=\mathrm{confidence}$ interval, $\mathrm{COPD}$ = chronic obstructive pulmonary disease, $\mathrm{Dr}=$ doctor, $\mathrm{ED}=$ emergency department, $\mathrm{EM}=$ emergency medicine, $\mathrm{FFS}=$ traditional fee-for-service, $\mathrm{FHG}=$ family health group (primarily FFS), $\mathrm{FHN}=$ family health network (primarily capitation-based), $\mathrm{FHO}=$ family health organization (primarily capitation-based), FHT = family health team, FM = family medicine. *Specialist includes cardiologist or internist. †Score of 1 is highest acuity. 
dictors of obtaining early physician follow-up included having a family physician, the remuneration method of that physician and the presence of substantial comorbidities (e.g., renal failure, chronic obstructive pulmonary disease, cancer). ${ }^{18}$ The outstanding clinical question was whether obtaining that follow-up care mattered. We are unaware of previous work that has evaluated the relationship between follow-up care after discharge from the emergency setting and long-term use of evidence-based medication. We surmise that, at the patient level, patients who are seen later, when the anxiety around the emergency visit has abated and no untoward events have occurred, are less motivated to use medication for hypertension long-term. Particularly for a disease that is usually asymptomatic, ${ }^{21}$ the opportunity to "strike while the iron is hot" may be in the early days after the emergency visit. Lack of symptoms and time from the event may explain waning antihypertensive adherence rates after a catastrophic event such as a stroke. ${ }^{22}$ Thus, increasing time from the emergency visit could also result in lower rates of long-term antihypertensive use.

At the physician level, later follow-up may allow the hypertension to decrease in health priority, as other health issues may have arisen subsequently. Health care team or system factors, such as access, may also contribute ${ }^{21}$ : patients who cannot obtain an earlier office appointment may be less likely to receive ongoing prescriptions from that office, particularly if there are adverse effects from an initial prescription that necessitate change. The lower odds of filling a prescription 1 year later among patients who present to the emergency department on the weekend (when access to primary care is reduced) may also be explained by poorer timely access to primary care. Finally, illness acuity could affect both follow-up and long-term medication use. Patients with more severe illness may be less able to attend appointments where antihypertensive medication is prescribed. Alternatively, patients with higher blood pressure values likely seek earlier follow-up care, and those patients may be more likely to be given a prescription to an antihypertensive agent and remain taking it, relative to patients with lower presenting values. However, we adjusted for triage score in our models, which directly correlate with presenting blood pressure values, ${ }^{23}$ as well as for many patient comorbidities and ambulance use, making this explanation less likely.

Among the myriad potential variables that we included in our models, only a few were independently associated with evidence-based medicine use 1 year later, and these associations were weaker than the timing of follow-up care. These included higher-acuity triage scores, which is expected given that patients with higher presenting blood pressure levels receive higher acuity scores: the Canadian Triage and Acuity Scale stipulates a higher acuity score for blood pressures > 200/110 mm Hg, and $>$ 220/130. ${ }^{24}$ Patients with a higher ADG score were less likely to be taking an antihypertensive agent 1 year later. This score is a measure of outpatient health care use, such as clinic appointments. ${ }^{19}$ Other studies have shown that the more medications a patient is taking (i.e., "prescription burden"), the less likely they are to adhere to a new medication. ${ }^{25} \mathrm{We}$ surmise that patients who use more outpatient health care resources are likely to be taking more medications overall, which may in turn reduce their likelihood of taking an additional medication or to adhere to it. ${ }^{25}$ In our second cohort, patients with a family physician who was remunerated with primarily capitation had more longterm prescription fills, consistent with previous work showing that capitation-based remuneration models are associated with better preventive care. ${ }^{26}$

\section{Limitations}

We restricted our patient population to people with a primary emergency department diagnosis of hypertension, because whether a secondary finding of hypertension during an emergency visit for something unrelated is the responsibility of emergency care is controversial, ${ }^{27}$ and because the codes for nonprimary diagnoses of hypertension have not been validated. The number of patients discharged with a nonprimary diagnosis of hypertension is likely substantially higher, and future work is needed to determine whether our results apply to these patients as well. We examined the effect of follow-up care on individual patients, not visits - we excluded repeat visits. We were interested in the overall effect of follow-up on evidence-based medication use, as opposed to the effect among frequent visitors to the emergency department. Our results do not include the latter effect. Although database studies offer population-based results, they often lack clinical-level data, such as blood pressure levels. It is possible that a small proportion of the cohort did not continue to have hypertension, and therefore did not require an antihypertensive medication. The higher the blood pressure reading, the more likely the patient is to continue to have hypertension, ${ }^{28}$ and among the patients with a primary diagnosis of hypertension in the emergency department, the median blood pressure was 181/97 (IQR 164200/85-109) mm Hg. ${ }^{6}$ A single reading of 180/110 mm Hg (either value) makes the diagnosis of hypertension (and therapy should be started). ${ }^{29}$ Emergency department studies have found that in anyone with a bloodpressure value higher than $140 / 90 \mathrm{~mm} \mathrm{Hg}$, regardless of the final diagnosis or the reason for the emergency visit (and their pain level), 77\% of patients had a persistently elevated reading post-visit, ${ }^{30}$ and $73 \%$ received a diagnosis of hypertension more than 1 year later. ${ }^{28}$ Therefore, it is likely that only a small proportion of patients in our study (all of whom had a primary diagnosis of hypertension) did not continue to have hypertension, in which case our results could be a small overestimate of the association.

Of the patients without care within 30 days, $2.7 \%$ had no relevant outpatient care in the year following discharge, which could make them unable to receive (and fill) an antihypertensive prescription if they did not return to an emergency department. However the proportion is small, and unlikely to substantially change our results. It remains that they should have filled such a prescription, if they continued to have hypertension (and the way to determine that begins with an outpatient visit), and all patients had a family physician. Although we adjusted for many potential confounders, without randomization, we cannot account for unmeasured confounders; randomization to early versus delayed follow-up care may not be ethical, potentially precluding a randomized trial on this topic. 


\section{Conclusion}

The results of this population-based study suggest that early follow-up after an emergency visit for hypertension may be an important factor that influences long-term use of evidence-based medication, being associated with a doubling in the number of persons who were taking an evidence-based antihypertensive agent 1 year later. By strengthening the transition of care between emergency and primary care, researchers, administrators and policy-makers may be able to capitalize on the steadily increasing emergency department visits for hypertension to improve the suboptimal rate of long-term use of preventive medication.

\section{References}

1. Vital signs: awareness and treatment of uncontrolled hypertension among adults - United States, 2003-2010. MMWR Morb Mortal Wkly Rep 2012;61:703-9.

2. Kearney PM, Whelton M, Reynolds K, et al. Global burden of hypertension: analysis of worldwide data. Lancet 2005;365:217-23.

3. Robitaille C, Dai S, Waters C, et al. Diagnosed hypertension in Canada: incidence, prevalence and associated mortality. CMA7 2012;184:E49-56.

4. Lim SS, Vos T, Flaxman AD, et al. A comparative risk assessment of burden of disease and injury attributable to 67 risk factors and risk factor clusters in 21 regions, 1990-2010: a systematic analysis for the Global Burden of Disease Study 2010. Lancet 2012;380:2224-60 [published erratum in Lancet 2013;381:628].

5. McNaughton CD, Self WH, Zhu Y, et al. Incidence of hypertension-related emergency department visits in the United States, 2006 to 2012. Am 7 Cardiol 2015;116:1717-23.

6. Masood S, Austin PC, Atzema CL. A population-based analysis of outcomes in patients with a primary diagnosis of hypertension in the emergency department. Ann Emerg Med 2016;68:258-67.

7. Cho DD, Austin PC, Atzema CL. Management of discharged emergency department patients with a primary diagnosis of hypertension: a multicentre study. C7EM 2015;17:523-31.

8. Daskalopoulou SS, Rabi DM, Zarnke KB, et al. The 2015 Canadian Hypertension Education Program recommendations for blood pressure measurement, diagnosis, assessment of risk, prevention, and treatment of hypertension. Can 7 Cardiol 2015;31:549-68.

9. National Ambulatory Care Reporting System (NACRS) metadata. Ottawa: Canadian Institute for Health Information. Available: https://www.cihi.ca/en/types-of -care/hospital-care/emergency-and-ambulatory-care/nacrs-metadata (accessed 2016 June 2).

10. Goel V, Williams JI, Anderson GM, et al., editors A summary of studies on the quality of health care administration databases in Canada. In: The ICES practice atlas: patterns of bealth care in Ontario. 2nd ed. Ottawa: Canadian Medical Association; 1996. Available: https://www.ices.on.ca/Publications/ Atlases-and-Reports/1996/Patterns-of-health-care-2nd-ed (accessed 2012 Sept. 6).

11. Canadian coding standards for Version 2012, ICD-10-CA and CCI. Ottawa: Canadian Institute for Health Information; 2012:5-15. Available: https://securecihica/ free_products/canadian_coding_standards_2012_epdf(accessed 2015 Dec. 17).

12. Iron K, Zagorski BM, Sykora K, et al. Living and dying in Ontario: an opportunity for improved health information. Toronto: Institute for Clinical Evaluative Sciences; 2008. Available: http://wwwicesonca/file/Living_and_dying in_Ontario_March19-08pdf (accessed 2012 Sept. 6).

13. Provider registry: privacy impact assessment summary. Toronto: eHealth Ontario; 2011. Available: https://www.ehealthontario.on.ca/images/uploads/ pages/.../ProviderRegistry_PIA.pdf (accessed 2017 Feb. 28).

14. Hamilton (ON): Ontario Physician Human Resources Data Centre. Available: https://wwwophrdcorg/Public/Reportaspx? owner=pio (accessed 2014 Sept. 12).

15. James PA, Oparil S, Carter BL, et al. 2014 evidence-based guideline for the management of high blood pressure in adults: report from the panel members appointed to the Eighth Joint National Committee (JNC 8). FAMA 2014;311:507-20.

16. Mancia G, Fagard R, Narkiewicz K, et al. 2013 ESH/ESC guidelines for the management of arterial hypertension: the Task Force for the management of arterial hypertension of the European Society of Hypertension (ESH) and of the European Society of Cardiology (ESC). $\mathcal{F}$ Hypertens 2013;31:1281-357.

17. Diggle P, Heagerty P, Liang KY, et al. Analysis of longitudinal data. 2nd ed. Toronto: Oxford University Press Canada; 2013.

18. Atzema CL, Yu B, Ivers NM, et al. Predictors of obtaining follow-up care in the province of Ontario, Canada, following a new diagnosis of atrial fibrillation, heart failure, and hypertension cardiovascular disease in the emergency department. CFEM;2017;14:1-15.

19. The Johns Hopkins ACG System. Baltimore (MD): Johns Hopkins University. Available: https://wwwhopkinsacgorg/ (accessed 2017 May 25).

20. Charlson ME, Pompei P, Ales KL, et al. A new method of classifying prognostic comorbidity in longitudinal studies: development and validation. $\mathcal{F}$ Chronic Dis 1987;40:373-83.
21. Sabate E. Adherence to long-term therapies: evidence for action. Geneva: World Health Organization; 2003.

22. Glader EL, Sjolander M, Eriksson M, et al. Persistent use of secondary preventive drugs declines rapidly during the first 2 years after stroke. Stroke 2010;41:397-401.

23. Murray M, Bullard M, Grafstein E, et al. Revisions to the Canadian Emergency Department Triage and Acuity Scale implementation guidelines. C7EM 2004;6:421-7.

24. Murray M, Bullard M, Grafstein E. Revisions to the Canadian emergency department triage and acuity scale implementation guidelines. CFEM 2004;6:421-7.

25. Benner JS, Chapman RH, Petrilla AA, et al. Association between prescription burden and medication adherence in patients initiating antihypertensive and lipid-lowering therapy. Am 7 Health Syst Pharm 2009;66:1471-7.

26. Kiran T, Victor JC, Kopp A, et al. The relationship between primary care models and processes of diabetes care in Ontario. Can 7 Diabetes 2014;38:172-8.

27. Kelen GD. Public health initiatives in the emergency department: not so good for the public health? Acad Emerg Med 2008;15:194-7.

28. Shiber-Ofer S, Shohat Z, Grossman A. Elevated diastolic, but not systolic, blood pressure measured in the emergency department predicts future development of hypertension in normotensive individuals. 7 Clin Hypertens (Greenwich) 2015;17:359-63.

29. Leung AA, Nerenberg K, Daskalopoulou SS, et al. Hypertension Canada's 2016 Canadian Hypertension Education Program guidelines for blood pressure measurement, diagnosis, assessment of risk, prevention, and treatment of hypertension. Can 7 Cardiol 2016;32:569-88

30. Backer HD, Decker L, Ackerson L. Reproducibility of increased blood pressure during an emergency department or urgent care visit. Ann Emerg Med $2003 ; 41: 507-12$.

Affiliations: Institute for Clinical Evaluative Sciences (Atzema, Yu, Schull, Jackevicius, Ivers, Lee, Rochon, Austin), Toronto, Ont.; Division of Emergency Medicine (Atzema, Schull) and Cardiology (Lee), the Department of Medicine, Department of Family and Community Medicine (Ivers), and the Institute for Health Policy, Management and Evaluation (Atzema, Schull, Jackevicius, Ivers, Lee, Rochon, Austin), University of Toronto, Toronto, Ont.; Sunnybrook Health Sciences Centre (Atzema, Schull, Tu, Austin), Women's College Hospital (Ivers, Rochon), University Health Network (Jackevicius, Lee), Toronto, Ont.; Western University of Health Sciences, Pomona, Calif., and the Veteran's Affairs Greater Los Angeles Healthcare System (Jackevicius), Los Angeles, Calif.

Contributors: All authors contributed to study concept and design. Clare Atzema acquired the data. Clare Atzema, Peter Austin and Bing Yu analyzed and interpreted the data. Clare Atzema drafted the manuscript. All authors critically revised the manuscript for important intellectual content. Clare Atzema, Peter Austin and Bing Yu performed the statistical analysis. All of the authors reviewed the accepted manuscript before publication and agreed to act as guarantors of the results.

Funding: This project was supported by a grant from the Canadian Institutes for Health Research (CIHR) (142415). Dr. Atzema is supported by a New Investigator Award from the Heart and Stroke Foundation (HSF), the Practice Plan of the Department of Emergency Services at Sunnybrook Health Sciences, and the Sunnybrook Research Institute. Dr. Schull was supported by an Applied Chair in Health Services and Policy Research from CIHR, Dr. Ivers was supported by a New Investigator Award from CIHR and a Clinician Scientist award from the Department of Family and Community Medicine, University of Toronto; Dr. Lee was supported by the Ted Rogers Chair in Heart Function Outcomes and a Mid-Career Investigator award from the HSF; Dr. Rochon holds the Retired Teachers of Ontario/ERO Chair in Geriatric Medicine; and Dr. Austin is supported by a Career Investigator Award from the HSF.

Disclaimer: The Heart and Stroke Foundation of Ontario had no involvement in the design or conduct of the study, data management or analysis, or manuscript preparation, review, or authorization for submission. This study was supported by the Institute for Clinical Evaluative Sciences (ICES), which is funded by an annual grant from the Ontario Ministry of Health and Long-Term Care (MOHLTC). The opinions, results and conclusions reported in this paper are those of the authors and are independent from the funding sources. No endorsement by ICES or the Ontario MOHLTC is intended or should be inferred.

Supplemental information: For reviewer comments and the original submission of this manuscript, please see www.cmajopen.ca/content/6/2/ E151/suppl/DC1. 